\title{
Atuação da Coordenação Pedagógica nos campi de Iguatu e Crato do Instituto Federal de Educação, Ciência e Tecnologia do Ceará.
}

\author{
Josefa Ataíde Gomes de Sousa ${ }^{1}$; Maria de Fátima Morais Alves ${ }^{2}$; \\ Márcia Leyla de Freitas Macêdo Felipe ${ }^{3}$; José Willame Felipe Alves ${ }^{4}$
}

\begin{abstract}
Resumo: Este trabalho teve como objetivo verificar a atuação da coordenação pedagógica nos campi de Iguatu e Crato do Instituto Federal de Educação, Ciência e Tecnologia do Ceará e como objetivos específicos: embasarse, teoricamente, o papel da coordenação pedagógica numa instituição de ensino, identificar o perfil dos seus profissionais, conhecer o trabalho que esta desenvolve e as dificuldades enfrentadas no cotidiano escolar. Para tanto, foram feitos estudos bibliográficos, abordando assuntos como conceitos e papéis desempenhados pela coordenação pedagógica, o cotidiano escolar nas instituições pesquisadas, as relações interpessoais, os desafios e as diversidades enfrentadas. Em seguida, foi aplicada uma pesquisa de campo, por meio de questionário com questões abertas e fechadas, envolvendo os servidores lotados nas coordenações pedagógicas das instituições pesquisadas, na qual foi possível constatar as formas como essas coordenações vêm desenvolvendo seus trabalhos no cotidiano. De acordo com os teóricos estudados, observamos que o coordenador pedagógico é peça fundamental no processo ensino-aprendizagem e que na sua função, deve articular as pessoas envolvidas, em especial os docentes, para a reflexão no seu contexto educacional de suas ações, dando a estes, subsídios, suporte pedagógico e orientações que venham contribuir para o crescimento profissional e, consequentemente uma maior qualidade no processo. Conforme a pesquisa aplicada, após a análise e discussão dos dados, constatou-se que os servidores das coordenações pedagógicas das instituições pesquisadas têm um nível de escolaridade compatível para o cargo, o que leva a crer que estes têm condições de desenvolver um bom trabalho. Além disso, observouse que as ações das coordenações pedagógicas das instituições pesquisadas são voltadas para o ensinoaprendizagem. Outro aspecto constatado foi sobre a formação continuada dos professores, que por meio das respostas dadas pelos entrevistados não ficou clara a maneira como esta acontece. Daí a confirmação de que não há uma ação planejada, organizada e contínua nesse sentido. A pesquisa revelou, também, que os servidores têm uma sintonia entre suas atribuições e o papel desenvolvido em seu cotidiano, embora, executem atividades que não consideram ser inerentes à sua função, por necessidade da instituição e que as dificuldades encontradas no cotidiano desses servidores são a falta de definição das reais atribuições da coordenação pedagógica, falta de compromisso de alguns para com as atividades a serem executadas, prejudicando, assim, os resultados dos trabalhos. Concluímos, que as coordenações pedagógicas das instituições pesquisadas estão no caminho certo, porém o campus de Iguatu, desenvolve um trabalho de forma mais integrada entre seus membros.
\end{abstract}

Palavras-chave:. Coordenação pedagógica. Ensino aprendizagem. Cotidiano escolar.

\section{The Performance of Pedagogical Coordination on campuses Iguatu Crato and the Federal Institute of Education, Science and Technology of Ceará.}

Abstract: This study aimed to determine the role of coordinating education campuses Iguatu Crato and the Federal Institute of Education, Science and Technology of Ceará and specific objectives: to base yourself, theoretically, the role of coordinating education at an educational institution, identify the profile of its professionals, know the work that develops and the difficulties faced in everyday school life. Therefore, studies were conducted bibliographic, addressing issues such as concepts and roles by coordinating education, the school routine in the institutions surveyed, interpersonal relationships, and the challenges faced diversities. Then, a search was applied field, through a questionnaire with open and closed questions, involving the crowded servers in coordinating educational institutions surveyed, in which it was possible to see the ways these coordinators are developing their work in everyday. According to the theoretical study, we observed that the pedagogical coordinator is instrumental in the teaching-learning process and in its function, must articulate the people involved, especially teachers, to reflect on their educational context of their actions, giving these, subsidies, educational support and guidance that may contribute to the professional growth and consequently a

\footnotetext{
${ }^{1}$ Instituto Federal do Ceará, campus Iguatu - ataide@ifce.edu.br

${ }^{2}$ Instituto Federal do Ceará, campus Iguatu - fatimamorais@ifce.edu.br

3 Intituto Federal do Ceará, campus Iguatu-marcia@ifce.edu.br

${ }^{4}$ nstituto Federal do Ceará, campus Cedro - willamefelipe@ ifce.edu.br
} 
higher quality in the process. As applied research, after analysis and discussion of the data, it was found that the servers of pedagogical coordinators of the institutions surveyed have a level of education consistent for the position, which suggests that they are able to develop a good work. Furthermore, it was observed that the actions of pedagogical coordinators of the institutions surveyed are geared towards teaching and learning. Another aspect was observed on the continuing education of teachers, which by the answers given by the respondents was not clear how this happens. Hence the confirmation that there is a planned action, organized and continuous accordingly. The research also revealed that the servers have a harmony between their assignments and role played in their daily lives, though, perform activities that do not consider to be inherent in his office, by necessity of the institution and that the difficulties encountered in the daily lives of these servers are failure to define the precise scope of the pedagogical coordination, lack of commitment by some toward the activities to be performed, and thus impair the results of the work. We conclude that the coordination of educational institutions surveyed are on the right track, but the campus Iguatu, carries out work in a more integrated among its members.

Keywords: Coordinating education, Teaching and learning; Everyday school

\section{Introdução}

A educação de qualidade tem sido uma busca constante das instituições de ensino, para que isso se torne realidade são necessárias ações que sustentem um trabalho em equipe e uma gestão que priorize a formação docente contribuindo para um processo pedagógico de qualidade. Nessa perspectiva, devemos identificar as necessidades dos professores e com eles encontrar soluções que priorizem um trabalho educacional de qualidade e esse trabalho deve ser mediado pelo coordenador pedagógico.

O desafio que a escola enfrenta exige dos profissionais da educação uma competência técnica e política que o habilitem a participar da construção da autonomia escolar construída a partir da autonomia garantida pela lei. Trata-se de coordenar o processo de organização das pessoas no interior da escola, buscando a convergência dos interesses dos seus vários segmentos e a superação dos conflitos decorrentes deles.

O coordenador pedagógico é o profissional que possui o importante papel de articular ações pedagógicas, viabilizando a qualidade no desempenho do processo ensino-aprendizagem.

Refletindo em torno do que foi citado acima, surgiu o interesse em desenvolver uma pesquisa para se ter um conhecimento mais aprofundado sobre o assunto, bem como, verificar, na prática, como se dá a atuação das coordenações pedagógicas nos campi Iguatu e Crato, do Instituto Federal de Educação, Ciência e Tecnologia do Ceará.

Para isso, colocou-se como objetivo geral da pesquisa verificar a atuação da coordenação pedagógica nos campi Iguatu e Crato, do Instituto Federal de Educação, Ciência e Tecnologia do Ceará. 


\section{Coordenação e coordenador pedagógico: Conceitos e papéis}

Conforme preceitua a Lei de Diretrizes e Bases da Educação Nacional (LDB) em seu Art. $1^{\circ}$, a educação abrange os processos formativos que se desenvolvem na vida familiar, na convivência humana, no trabalho, nas instituições de ensino e pesquisa, nos movimentos sociais e organizações da sociedade civil e nas manifestações culturais. (Brasil, 1996).

O perfil da educação brasileira apresentou significativas mudanças nas últimas décadas. Houve substancial queda na taxa de analfabetismo, aumento expressivo do número de matrículas em todos os níveis de ensino. Um dos fatores que contribuíram consideravelmente para essa melhoria foi a exigência legal de formação inicial para sua atuação, tanto para professores, como também para os profissionais técnicos pedagógicos, pois nem sempre essa função era cumprida por especialistas, devido à deficiência de profissionais habilitados e do próprio sistema educacional.

De acordo com o dicionário Aurélio (1977, p. 32), coordenar é o mesmo que "ligar, ajuntar, organizar, arranjar", já o termo coordenação significa "mediar, ligar, articular um trabalho em andamento"

A palavra coordenador, refere-se ao "indivíduo incumbido de orientar, harmonizar, coordenar o trabalho de um grupo" (Larousse Cultural, 1998, p. 92).

Já a palavra coordenação encontra-se vinculada à ideia de organização, de ação efetiva, no sentido de realizar trabalho voltado para a construção da identidade coletiva ou para o reconhecimento recíproco do trabalho e das competências de todos.

Para a autora Placco (2003, p. 47), o coordenador pedagógico é aquele que organiza, orienta e harmoniza o trabalho de um grupo, por intermédio de determinados métodos, de acordo com o sistema ou contexto em que se insere.

O Coordenador Pedagógico é o profissional que, na escola, possui o importante papel de desenvolver e articular ações pedagógicas que viabilizem a qualidade no desempenho do processo ensino-aprendizagem, oferecendo as melhores condições de ensino e facilitando o relacionamento professor-aluno.

Para Lück (1991, p. 63):

O papel do supervisor escolar se constitui, em última análise, na somatória de esforços e ações desencadeados com o sentido de promover a melhoria do processo ensino-aprendizagem. Esse esforço voltou-se constantemente ao professor, num processo de assistência aos mesmos e coordenação de sua ação.

De acordo com Souza e Placco (2007, p. 34), o coordenador pedagógico é o profissional, dentro da escola, que pode tomar para si a tarefa de desenvolver processos que viabilizem a construção da autoridade, através da formação de valores como o respeito, a responsabilidade, a admiração e a 
autonomia. Ele pode ser o mediador desse processo, aquele que o propõe, o coordena, mas não é o responsável único por ele, o que deve ser assumido por toda equipe da escola.

O coordenador pedagógico não deve se sentir o único responsável pelo sucesso do processo ensino-aprendizagem, ele é um dos responsáveis, necessitando, portanto, do empenho de toda a comunidade escolar.

Segundo Placco (2003, p. 51),

Nenhum processo de planejamento e de desenvolvimento profissional, na escola, tem resultados efetivos se a responsabilidade pelos processos e pelos resultados não é partilhada - cada qual com a função que lhe cabe, mas consciente das funções uns dos outros e colaborando mutuamente para que os objetivos sejam alcançados.

A busca da informação e do conhecimento deve estar sempre presente no cotidiano do coordenador pedagógico, para assim, dá um melhor retorno à sua equipe. Freire (1982, p. 95), afirma que:

\begin{abstract}
O supervisor é um educador e, se ele é um educador, ele não escapa na sua prática a essa natureza epistemológica da educação. Tem a ver com o conhecimento, com a teoria do conhecimento. O que se pode perguntar é: Qual o objeto de conhecimento que interessa diretamente ao supervisor? Aí talvez a gente pudesse dizer: é o próprio ato de conhecimento que está se dando na relação educador/educando.
\end{abstract}

Um coordenador pedagógico comprometido com seu papel de educador, cujos princípios de educação democrática constituem sua concepção do que deve ser educação, investirá na construção de uma autoridade que exclui a coerção como meio de conquista, exercitando a responsabilidade, o autorespeito e a autonomia.

La Taille apud Souza e Placco (2007, p. 42), diz que o respeito, a hierarquia e a autonomia constituem-se em condição para a existência da autoridade. Isso porque o fato de alguém obedecer à determinada ordem não significa que o mandante tenha autoridade, se não estão presentes o respeito e a autonomia de quem obedece.

Em entrevista apud Souza e Placco (2007, p. 44), um jovem músico afirmou:

Nós nos juntamos pela afinidade, porque tínhamos um objetivo comum, e não porque éramos iguais. Só que afinidade era somente o começo, o ponto de partida para descobrirmos as diferenças de cada um, e crescer com elas. Quando descobrimos que somos diferentes podemos compreender as razões de cada um, as motivações para as atitudes, e não mais avaliar somente atitudes.

Esse depoimento traduz o que realmente são valores e seu processo de constituição. O coordenador pedagógico precisa compreender e respeitar os valores dos outros. Somente assim podese investir na formação de valores, sem correr o risco de cair no autoritarismo, em que valores de grupos hegemônicos seriam postos como os melhores e únicos possíveis. 
O trabalho da coordenação é atender necessidades e prever ações que possam garantir o bom andamento do processo ensino-aprendizagem. Esse trabalho só poderá ser desenvolvido através do trabalho em equipe, com a colaboração de todos os sujeitos envolvidos com esse processo: alunos, pais, funcionários, professores, coordenadores e direção.

Para Souza (2007, p. 32), a existência de um grupo é a condição primeira para a atividade do(a) coordenador(a), uma vez que ele vai trabalhar na liderança de pessoas que desenvolvem um trabalho comum, no caso professores. Lidar com grupos implica lidar com diferenças, o que equivale a enfrentar conflitos e buscar caminhos para superá-los.

O coordenador pedagógico é o profissional que na unidade escolar responde fundamentalmente pelo processo de formação continuada dos educadores e pelo projeto de construção da relação teoria e prática dos docentes.

É o mediador que articula a construção coletiva do projeto político-pedagógico da escola e que, em comunhão com os professores, elabora a qualidade das práticas educativas, favorecendo também, nesse processo, o crescimento intelectual, afetivo e ético dos educadores e alunos.

Segundo Orsolon (2007, p. 72), o coordenador pedagógico para direcionar suas ações para a transformação, deverá estar consciente de que seu trabalho não se dá isoladamente, mas nesse coletivo, mediante a articulação dos diferentes atores escolares, no sentido da construção de um projeto político-pedagógico transformador.

Entretanto, o coordenador pedagógico deve ser um profissional capaz de articular toda a comunidade escolar, para o desempenho das atividades inerentes à escola, fazendo com que cada um faça a sua parte e depois possa juntar-se ao todo, para o efetivo sucesso escolar, que tem como resultado a melhoria do processo ensino-aprendizagem.

\section{O Coordenador Pedagógico e o Cotidiano Escolar}

Um profissional para trabalhar com a dinâmica dos processos de coordenação pedagógica na escola precisa antes de tudo, ter a convicção de que qualquer situação educativa é complexa, permeada de conflitos de valores, percalços e perspectivas.

Segundo Souza (2003, p. 25), outro caminho para enfrentar a complexidade é pensar a instituição de forma sistêmica, o que significa compreender o seu todo - interno e externo - com suas contradições e implicações. Ou seja, trabalhar com todos os grupos pertencentes ao universo escolar de forma conjunta, com o pensamento sistêmico, no intuito de atingir os objetivos gerais da escola, cada um fazendo a sua parte e depois, juntando-se ao todo. 
O cotidiano dos coordenadores pedagógicos na escola é repleto de imprevistos, de situações de emergências, de urgências que fogem ao controle, ao planejado. Este então, deve estar preparado para conviver com essas adversidades.

Franco $(2008$, p. 87) em pesquisa realizada com coordenadores pedagógicos de escolas públicas, observou que, "as escolas são percebidas

As escolas são percebidas pelos coordenadores como espaços de poucos planejamentos e muita improvisação e as atividades cotidianas são conduzidas por ações espontaneístas, emergenciais, superficiais, baseadas no bom senso.

Muitas são as queixas relatadas por coordenadores pedagógicos em seu cotidiano, a falta de tempo para executar as tarefas planejadas, situações de emergências, sobrecarga de trabalho e carência de pessoal.

O dia-a-dia do coordenador exige que faça uma boa administração do seu tempo, para assim, tentar cumprir as inúmeras tarefas que lhe são propostas a cada dia. Tarefas como planejar reuniões, acompanhar a prática do professor em sala de aula, conversar com pais, encaminhar alunos com problemas a especialistas, conversar com professor, isso sem falar numa infinidade de atividades burocráticas que precisam ser desenvolvidas durante o seu expediente.

Vasconcellos (2002, p. 53) defende que o coordenador pedagógico deverá ter seu próprio projeto de trabalho, assim como, o professor deve ter seu plano de aula, e que esse projeto deve está em consonância com o projeto político-pedagógico da escola.

E para elaborar sua proposta de trabalho deverá ter metas a alcançar e os meios para atingi-las. Portanto, Almeida (2003, p. 64) cita três tipos de decisões que lhes são exigidas para isto:

1. Quais modificações sua proposta vai ocasionar, ou seja: a) a seleção de objetivos: valiosos, porque éticos, ao considerar que todas as pessoas devem ser reconhecidas e respeitadas, e exequíveis, porque dentro das possibilidades do momento; b) estabelecimento de prioridades;

2. O que pretende fazer para atingir os objetivos;

3. Como saber se a proposta foi adequada (avaliação dos objetivos e meios).

Mesmo que o coordenador elabore seu projeto de trabalho, sabe-se que na prática nem sempre é possível cumpri-lo à risca, devido a uma imensidão de afazeres extras que surgem, que às vezes são de sua competência e outras nem o são, no entanto, acaba fazendo um pouco o papel do coringa na instituição.

O autor Matus apud Placco (2003, p. 70) caracteriza as atividades cotidianas de trabalho em quatro conceitos: IMPORTÂNCIA - ROTINA - URGÊNCIA - PAUSA, que devem ser observadas pelos coordenadores pedagógicos em suas ações cotidianas. 
As atividades de IMPORTÂNCIA são aquelas descritas em seu projeto de trabalho e de acordo com o projeto político-pedagógico. São estabelecidas como ações de prioridades para o atendimento às necessidades pedagógicas da escola.

Já as atividades de ROTINA dizem respeito ao funcionamento da escola em seu cotidiano, para a manutenção de procedimentos e recursos de trabalho. Tanto as atividades de rotina como as atividades de importância são planejadas previamente, constituindo-se assim um pouco na organização da escola.

As atividades de URGÊNCIA e de PAUSA são decorrentes da dinâmica da escola e das necessidades urgentes do cotidiano. As urgências são os "incêndios" surgidos no cotidiano, que precisam ser apagados de imediato, como por exemplo, a falta de um professor à aula, faltas de equipamentos, de recursos ou outras eventualidades.

O ser humano não vive só de trabalho, as pausas são essenciais para que se possa desenvolver um trabalho de qualidade.

Placco (2003, p. 57) diz que,

Nenhum processo de planejamento e de desenvolvimento profissional, na escola tem resultados efetivos se a responsabilidade pelos processos e pelos resultados não é partilhada - cada qual com a função que lhe cabe, mas consciente das funções uns dos outros e colaborando mutuamente para que os objetivos sejam alcançados.

O coordenador pedagógico deve está atento à sua realidade e à realidade escolar como um todo, analisando alternativas e indicando caminhos para a superação de obstáculos enfrentados no cotidiano da escola.

\section{Metodologia}

O trabalho, inicialmente, foi caracterizado como pesquisa bibliográfica, que conforme Santos (2001, p. 41), 'é a utilização de escritos que contêm informações já elaboradas e publicadas por outros autores, são exemplos de fontes bibliográficas, os livros, as publicações periódicas (jornais, revistas), fitas de áudio e vídeo, web sites, seminários, "'.

Para atingir os objetivos do trabalho, foi feita a coleta de dados, por meio de uma pesquisa de campo, que é uma das fontes de informações. Segundo Santos (2001, p. 44), '’a pesquisa de campo é a que recolhe os dados in natura, como percebidos pelo pesquisador'. 


\section{Descrição do universo da pesquisa e amostragem}

O universo da pesquisa foram os servidores lotados nas Coordenações Pedagógicas dos campi de Iguatu e Crato, do Instituto Federal do Ceará, antigas Escolas Agrotécnicas Federais. Os campi foram escolhidos dentre os 23 campi que compõem o Instituto citado, devido a proximidade geográfica, como também pela filosofia de trabalho, voltado para a área agrícola.

\section{Instrumentos utilizados para a coleta de dados e análises}

Visando atingir os objetivos traçados para a pesquisa, utilizou-se como instrumento de coleta de dados um questionário, composto de dez questões abertas e de múltipla escolha.

Após a coleta de dados, realizou-se a discussão e a análise estatística desses dados, que foram apresentados em forma de tabela, conforme se pode perceber na sequência deste trabalho.

\section{Resultados obtidos na pesquisa de campo}

De acordo com o questionário aplicado aos servidores da coordenação pedagógica dos campi de Iguatu e Crato do Instituto Federal do Ceará.

O questionário que foi aplicado ao universo dos servidores da Coordenação Pedagógica do campi Iguatu, num total de três, sendo a coordenadora pedagógica e 02 pedagogas. A Coordenação Pedagógica do campi Crato conta com um total de seis servidores, sendo quatro Técnicos em Assuntos Educacionais, um Orientador educacional e a Coordenadora pedagógica. Destes, um deixou de responder ao questionário por não se encontrar na instituição no dia da pesquisa. Portanto, o questionário foi aplicado aos servidores presentes, isto é, cinco.

Após a coleta de dados, realizou-se a devida tabulação e em seguida, a apresentação e a análise desses dados. Levando-se em consideração os resultados obtidos, optamos em discutir cada quesito do questionário, apresentando as respectivas tabelas, para maior clareza na análise. 
Tabela 01: SEXO DOS ENTREVISTADOS

\begin{tabular}{l|c|c|c|c}
\hline \multirow{2}{*}{\multicolumn{2}{c|}{ RESPOSTAS }} & \multicolumn{2}{c|}{ campus Iguatu } & \multicolumn{2}{c}{ campus Crato } \\
\cline { 2 - 5 } & $\mathrm{N}^{\circ}$ SERV. & $\%$ & $\mathrm{~N}^{\circ}$ SERV. & $\%$ \\
\hline Feminino & 03 & 100 & 03 & 60,00 \\
Masculino & - & - & 01 & 20,00 \\
Não respondeu & - & - & 01 & 20,00 \\
\hline TOTAL & 03 & 100 & 05 & 100 \\
\hline
\end{tabular}

Fonte: Questionário aplicado às Coordenações Pedagógicas dos campi Iguatu e Crato - CE

Para a primeira pergunta do questionário, que indagou sobre o sexo dos servidores pesquisados, obtivemos as seguintes respostas: a totalidade dos servidores do campus Iguatu respondeu ser do sexo feminino, ao passo que $60 \%$ dos entrevistados do campus Crato responderam ser do sexo feminino, $20 \%$ do sexo masculino e $20 \%$ não quiseram responder ao questionário, alegando falta de tempo, conforme mostra a tabela acima:

Como pode ser observado na tabela acima, a maioria dos servidores das coordenações pedagógicas é do sexo feminino. Isso nos revela, ser uma área com maior atuação feminina.

Tabela 02: ESCOLARIDADE.

\begin{tabular}{l|c|c|c|c}
\hline \multirow{2}{*}{ RESPOSTAS } & \multicolumn{2}{|c|}{ campus Iguatu } & \multicolumn{2}{c}{ campus Crato } \\
\cline { 2 - 6 } & $\begin{array}{c}\mathrm{N}^{\mathbf{0}} \\
\text { SERV. }\end{array}$ & $\%$ & $\begin{array}{c}\mathrm{N}^{\mathbf{0}} \\
\text { SERV. }\end{array}$ & $\%$ \\
\hline - Graduado em História & - & - & 01 & 20,00 \\
- Graduado em Pedagogia e Especialista em Educação & 02 & 66,67 & 02 & 40,00 \\
- Graduado em Letras e Especialista em Língua & 01 & 33,33 & - & - \\
Portuguesa & & & & \\
- Graduado em Biologia e Especialista em Educação & - & - & 01 & 20,00 \\
- Não respondeu & - & - & 01 & 20,00 \\
\hline TOTAL & 03 & 100 & 05 & 100 \\
\hline
\end{tabular}

Fonte: Questionário aplicado às Coordenações Pedagógicas dos campi Iguatu e Crato - CE

A segunda questão, que tratou da escolaridade dos entrevistados, apontou que quase $100 \%$ dos servidores das instituições pesquisadas têm escolarização em nível de pós-graduação (especialização). Dos servidores pesquisados do campus Iguatu, 66,67\% têm especialização na área de educação e 
somente 33,33\% têm especialização em outra área. No campus Iguatu, $20 \%$ dos servidores têm apenas graduação, $60 \%$ têm especialização na área de educação e $20 \%$ não responderam.

Observou-se, nesse caso, que da totalidade dos servidores entrevistados campus Iguatu, 33,33\% não possuem formação na área de Pedagogia, porém, possuem graduação em Letras, que é uma área afim. Constatamos, portanto, que a coordenação pedagógica do campus Iguatu está bem estruturada quanto à qualificação dos seus profissionais, aptos ao bom desenvolvimento de suas atividades. Em relação a este aspecto, os servidores da coordenação pedagógica campus Crato, também, encontram-se em situação favorável, pois $20 \%$ têm graduação em História, área afim.

Tabela 03: CARGO OCUPADO NA INSTITUIÇÃO.

\begin{tabular}{l|c|c|c|c}
\hline \multirow{2}{*}{\multicolumn{1}{c|}{ RESPOSTAS }} & \multicolumn{2}{c|}{ campus Iguatu } & \multicolumn{2}{c}{ campus Crato } \\
\cline { 2 - 5 } & $\mathrm{N}^{\circ}$ SERV. & $\%$ & $\mathrm{~N}^{\circ}$ SERV. & $\%$ \\
\hline - Assistente em administração & 01 & 33,33 & - & - \\
- Supervisor & 01 & 33,33 & 01 & 20,00 \\
- Pedagogo & 01 & 33,34 & - & - \\
- Técnico em Assuntos Educacionais & - & - & 03 & 60,00 \\
- Não respondeu & - & - & 01 & 20,00 \\
\hline TOTAL & 03 & 100 & 05 & 100 \\
\hline
\end{tabular}

Fonte: Questionário aplicado às Coordenações Pedagógicas dos campi Iguatu e Crato - CE

Em relação à terceira questão, que indagou sobre o cargo ocupado pelos entrevistados na instituição, obtivemos como respostas: No campus Iguatu, 33,33 \% dos entrevistados ocupam cargo de Supervisor, 33,33 \% ocupam o cargo de Pedagogo e 33,34\% ocupam o cargo de Assistente em Administração e no campus Crato, 20\% são Supervisores, 60\% Técnicos em Assuntos Educacionais e $20 \%$ não responderam, conforme informações expostas na tabela acima.

Observou-se, na Tabela 03, que o número de servidores na Coordenação Pedagógica d campus Iguatu é reduzido, por isso contar com um profissional, que não é da área, desenvolvendo o trabalho. Diferentemente, o campus Crato, tem um número razoável de servidores, além de cargos variados e dentro da área, que teoricamente, poderá facilitar o desenvolvimento do trabalho na coordenação pedagógica. 
Tabela 04: TEMPO DE ATUAÇÃO DOS SERVIDORES.

\begin{tabular}{l|c|c|c|c}
\hline \multirow{2}{*}{\multicolumn{1}{c|}{ RESPOSTAS }} & \multicolumn{2}{c|}{ campus Iguatu } & \multicolumn{2}{c}{ campus Crato } \\
\cline { 2 - 5 } & $\mathrm{N}^{\circ}$ SERV. & $\%$ & $\mathrm{~N}^{\circ}$ SERV. & $\%$ \\
\hline - de 0 a 10 anos & 02 & 66,67 & 03 & 60,00 \\
- de 11 anos acima & 01 & 33,33 & 01 & 20,00 \\
- Não respondeu & - & - & 01 & 20,00 \\
\hline TOTAL & 03 & 100 & 05 & 100 \\
\hline
\end{tabular}

Fonte: Questionário aplicado às Coordenações Pedagógicas dos campi Iguatu e Crato - CE

Na questão quatro, procurou-se saber o tempo de atuação dos entrevistados na coordenação pedagógica e obtiveram-se os resultados descritos na Tabela 04.

Constatou-se, com base nesses dados da Tabela acima, que os profissionais atuantes na coordenação têm um bom tempo de trabalho, levando-nos a crer que isto faça com que o profissional melhore cada vez mais, pois, além da qualificação de cada um, o tempo de trabalho é responsável pela experiência e o amadurecimento profissional na área em que atua.

Tabela 05: ESPECIFICIDADE DO TRABALHO DA COORD.PEDAGÓGICA

\begin{tabular}{|c|c|c|c|c|}
\hline \multirow[b]{2}{*}{ RESPOSTAS } & \multicolumn{2}{|c|}{ campus Iguatu } & \multicolumn{2}{|c|}{ campus Crato } \\
\hline & $\mathrm{N}^{\mathrm{o}} \mathrm{SERV}$ & $\%$ & $\begin{array}{c}\mathrm{N}^{\mathrm{o}} \\
\text { SERV. }\end{array}$ & $\%$ \\
\hline - O processo ensino-aprendizagem; & 02 & 66,67 & 02 & 40,00 \\
\hline - Orientar e supervisionar o trabalho docente; & 01 & 33,33 & 01 & 20,00 \\
\hline - Qualificação do profissional; & - & - & 01 & 20,00 \\
\hline - Não respondeu & - & - & 01 & 20,00 \\
\hline TOTAL & 03 & 100 & 05 & 100 \\
\hline
\end{tabular}

Fonte: Questionário aplicado às Coordenações Pedagógicas dos campi Iguatu e Crato - CE

A quinta questão indagou sobre a especificidade do trabalho da coordenação pedagógica na instituição e obtiveram-se os resultados expostos na Tabela acima.

Observou-se os seguintes resultados: Com relação ao campus Iguatu, 66,67\% disseram ser o processo ensino-aprendizagem e 33,33\% opinaram por ser a assistência e o acompanhamento ao professor. Dos entrevistados do campus Crato, $40 \%$ disseram ser o processo ensino-aprendizagem, $20 \%$ responderam que seria orientar e supervisionar o trabalho docente, $20 \%$ deram como resposta a qualificação profissional e $20 \%$ não responderam. 
O núcleo de definição e de articulação da supervisão deve ser, portanto, o pedagógico (que é o núcleo da escola, enquanto especificidade institucional) e, em especial, os processos de ensinoaprendizagem. (VASCONCELLOS, 2002, p. 114)

Portanto, a coordenação pedagógica deve ter como foco principal de sua atuação o processo ensino-aprendizagem, que se dá por meio da formação continuada, do projeto político-pedagógico, orientação aos docentes e os processos avaliativos.

As respostas obtidas demonstram que os profissionais que atuam na coordenação pedagógica do campus Iguatu têm ciência do seu papel específico, enquanto o campus Crato necessita buscar, em grupo, uma afinidade maior, no intuito de desenvolver um trabalho mais integrado no processo ensinoaprendizagem.

Tabela 06: ATRIBUIÇÕES DA COORDENAÇÃO PEDAGÓGICA.

\begin{tabular}{|c|c|c|c|c|}
\hline \multirow[b]{2}{*}{ RESPOSTAS } & \multicolumn{2}{|c|}{ campus Iguatu } & \multicolumn{2}{|c|}{ campus Crato } \\
\hline & $\begin{array}{c}\mathrm{N}^{\mathrm{o}} \\
\text { SERV. }\end{array}$ & $\%$ & $\mathrm{~N}^{\circ}$ SERV. & $\%$ \\
\hline $\begin{array}{l}\text { - Atendimento a professores por questões pedagógicas; } \\
\text { formação continuada dos professores; articular a } \\
\text { elaboração do projeto político-pedagógico da } \\
\text { instituição; reuniões pedagógicas; atendimento a pais; } \\
\text { planejamento e/ou elaboração de projetos, apostilas, } \\
\text { materiais pedagógicos; atividades administrativas e/ou } \\
\text { burocráticas e organização de eventos na escola. } \\
\text { - Atendimento a professores por questões pedagógicas; } \\
\text { formação continuada dos professores; articular a } \\
\text { elaboração do projeto político-pedagógico da } \\
\text { instituição; reuniões pedagógicas; atendimento a pais; } \\
\text { planejamento e/ou elaboração de projetos, apostilas, } \\
\text { materiais pedagógicos; atividades administrativas e/ou } \\
\text { burocráticas; organização de eventos na escola; } \\
\text { controle movimento/fluxo dos alunos na entrada e } \\
\text { saída; Outros (acompanhar e analisar o processo } \\
\text { avaliativo, participar do conselho de classe) } \\
\text { - Atendimento a professores por questões pedagógicas; } \\
\text { articular a elaboração do projeto político-pedagógico da } \\
\text { instituição; reuniões pedagógicas; atendimento a pais; } \\
\text { planejamento e/ou elaboração de projetos, apostilas, } \\
\text { materiais pedagógicos; substituição de professores; } \\
\text { controle movimento/fluxo dos alunos na entrada e } \\
\text { saída. } \\
\text { - Não respondeu } \\
\text { TOTAL }\end{array}$ & $\begin{array}{c}- \\
- \\
03\end{array}$ & 66,67 & $\begin{array}{l}01 \\
01 \\
05\end{array}$ & $\begin{array}{c}20,00 \\
20,00 \\
100\end{array}$ \\
\hline
\end{tabular}

Fonte: Questionário aplicado às Coordenações Pedagógicas dos campi Iguatu e Crato - CE 
Já com relação à questão seis, foram dadas opções para que os entrevistados marcassem o que considerassem ser atribuições da coordenação pedagógica e mais a opção outros, para acrescentar o que não foi citado, obtendo-se as seguintes respostas: 66,67\% do campus Iguatu e 60\% do campus Crato consideraram atribuições: atendimento a professores por questões pedagógicas; formação continuada dos professores; articular a elaboração do projeto político-pedagógico da instituição; reuniões pedagógicas; atendimento a pais; planejamento e/ou elaboração de projetos, apostilas, materiais pedagógicos; atividades administrativas e/ou burocráticas e organização de eventos na escola; 33,33\% do campus Iguatu deram como resposta: atendimento a professores por questões pedagógicas; formação continuada dos professores; articular a elaboração do projeto políticopedagógico da instituição; reuniões pedagógicas; atendimento a pais; planejamento e/ou elaboração de projetos, apostilas, materiais pedagógicos; atividades administrativas e/ou burocráticas; organização de eventos na escola; controle movimento/fluxo dos alunos na entrada e saída; Outros (acompanhar e analisar o processo avaliativo, participar do conselho de classe); $20 \%$ dos entrevistados do campus Crato responderam: atendimento a professores por questões pedagógicas; articular a elaboração do projeto político-pedagógico da instituição; reuniões pedagógicas; atendimento a pais; planejamento e/ou elaboração de projetos, apostilas, materiais pedagógicos; substituição de professores; controle movimento/fluxo dos alunos na entrada e saída e $20 \%$ não responderam.

Desse modo, observou-se que os entrevistados divergiram em suas respostas nos pontos: controle movimento/fluxo dos alunos na entrada e saída; substituição de professores e Outros (acompanhar e analisar o processo avaliativo, participar do conselho de classe), mas que no geral, estão dentro de um nível de conhecimento satisfatório de suas atribuições.

Tabela 07: ATIVIDADES EXECUTADAS NO COTIDIANO ESCOLAR.

\begin{tabular}{|c|c|c|c|c|}
\hline \multirow[b]{2}{*}{ RESPOSTAS } & \multicolumn{2}{|c|}{ campus Iguatu } & \multicolumn{2}{|c|}{ campus Crato } \\
\hline & $\mathrm{N}^{\circ}$ SERV. & $\%$ & $\mathrm{~N}^{\circ}$ SERV & $\%$ \\
\hline $\begin{array}{l}\text { - Atendimento a professores por questões pedagógicas; } \\
\text { formação continuada dos professores; articular a elaboração } \\
\text { do projeto político-pedagógico da instituição; reuniões } \\
\text { pedagógicas; atendimento a pais; atividades administrativas } \\
\text { e/ou burocráticas; controle movimento/fluxo dos alunos na } \\
\text { entrada e saída e Outros (acompanhar e analisar o processo } \\
\text { avaliativo e participar dos órgãos colegiados, proteger o } \\
\text { tempo de aprendizado dos alunos, evitando aulas vagas). }\end{array}$ & 01 & 33,33 & 01 & 20,00 \\
\hline $\begin{array}{l}\text { - Atendimento a professores por questões pedagógicas; } \\
\text { formação continuada dos professores; articular a elaboração } \\
\text { do projeto político-pedagógico da instituição; reuniões } \\
\text { pedagógicas; atendimento a pais; planejamento e/ou } \\
\text { elaboração de projetos, apostilas, materiais pedagógicos, } \\
\text { etc. e organização de eventos da escola - festas, reuniões, } \\
\text { etc. } \\
\text { (Continua...) }\end{array}$ & 02 & 66,67 & 02 & 40,00 \\
\hline
\end{tabular}




\begin{tabular}{l|c|c|c|c}
\hline - Atendimento a professores por questões pedagógicas; & & & & \\
articular a elaboração do projeto político-pedagógico da \\
instituição; atendimento a pais; organização de eventos da \\
escola - festas, reuniões, etc. e controle movimento/fluxo \\
dos alunos na entrada e saída.
\end{tabular}

Fonte: Questionário aplicado às Coordenações Pedagógicas dos campi Iguatu e Crato - CE

Em relação à questão sete, foram dadas as mesmas opções da questão seis para que os entrevistados marcassem as opções que se encaixasse nas tarefas executadas no seu cotidiano escolar.

Observou-se que $33,33 \%$ dos entrevistados do campus Iguatu e $20 \%$ do campus Crato desempenham as atividades propostas na questão, além de outras que citaram, como a participação nos órgãos colegiados, análise do processo avaliativo, proteger o tempo de aprendizado dos alunos, evitando aulas vagas; 66,67\% dos entrevistados do campus Iguatu e $40 \%$ do campus Crato responderam: atendimento a professores por questões pedagógicas; formação continuada dos professores; articular a elaboração do projeto político-pedagógico da instituição; reuniões pedagógicas; atendimento a pais; planejamento e/ou elaboração de projetos, apostilas, materiais pedagógicos, etc. e organização de eventos da escola - festas e reuniões; $20 \%$ responderam: Atendimento a professores por questões pedagógicas; articular a elaboração do projeto políticopedagógico da instituição; atendimento a pais; organização de eventos da escola - festas, reuniões, etc. e controle movimento/fluxo dos alunos na entrada e saída e $20 \%$ não responderam.

Isso implica dizer que as atividades desenvolvidas no cotidiano escolar vão além das atribuições da coordenação pedagógica, dificultando, assim, o trabalho, deixando-se, muitas vezes, de fazer o mais importante para se fazer o mais urgente.

Tabela 08: PARTICIPAÇÃO NA FORMAÇÃO CONTINUADA DOS PROFESSORES.

\begin{tabular}{|c|c|c|c|c|}
\hline \multirow[b]{2}{*}{ RESPOSTAS } & \multicolumn{2}{|c|}{ campus Iguatu } & \multicolumn{2}{|c|}{ campus Crato } \\
\hline & $\mathrm{N}^{\circ}$ SERV. & $\%$ & $\mathrm{~N}^{\circ}$ SERV. & $\%$ \\
\hline $\begin{array}{l}\text { - Propiciando condições para que o professor faça de sua } \\
\text { prática objeto de reflexão e pesquisa; } \\
\text { - Articulando a participação dos docentes em cursos de } \\
\text { formação, entre outros. } \\
\text { - Auxiliando os professores no que diz respeito ao ensino e } \\
\text { aprendizagem; } \\
\text { - Apresentando suas opiniões na qualificação dos } \\
\text { educadores; } \\
\text { - Não sabe; } \\
\text { - Não respondeu }\end{array}$ & $\begin{array}{l}01 \\
01 \\
- \\
- \\
- \\
\end{array}$ & $\begin{array}{l}33,33 \\
33,33 \\
33,34 \\
- \\
- \\
-\end{array}$ & $\begin{array}{l}- \\
01 \\
01 \\
02\end{array}$ & $\begin{array}{r}- \\
20,00 \\
- \\
20,00 \\
20,00 \\
40,00\end{array}$ \\
\hline TOTAL & 03 & 100 & 05 & 100 \\
\hline
\end{tabular}

Fonte: Questionário aplicado às Coordenações Pedagógicas dos campi Iguatu e Crato - CE 
Para a questão oito, que indagou aos entrevistados quanto à participação na formação continuada dos professores e de que forma isso se dava, foram obtidos os seguintes resultados: $33,33 \%$ dos servidores do campus Iguatu disseram que propiciando condições para que o professor faça de sua prática objeto de reflexão e pesquisa; 33,33\% campus Iguatu e $20 \%$ do campus Crato responderam que se daria articulando a participação dos docentes em cursos de formação, entre outros, $33 \%$ do campus Iguatu disseram ser auxiliando os professores no que diz respeito ao ensino e aprendizagem, $20 \%$ do campus Crato responderam ser apresentando suas opiniões na qualificação dos educadores, $20 \%$ não sabem e $20 \%$ não resp.onderam.

Para Prada (2008, p. 28), a formação continuada acontece mediante diversas situações do cotidiano que viabilizem aprendizagens para o exercício profissional. É aquela desenvolvida, geralmente, mediante atividades de estudo e pesquisa planejadas e realizadas como parte do desenvolvimento profissional dos professores a partir das necessidades e conhecimentos derivados das suas experiências docentes.

Percebe-se, diante das respostas dadas pelos entrevistados, que existe uma ideia do que seja a formação continuada, mas não ficou claramente definido, de forma prática, como é feita essa formação com os professores.

O trabalho do Coordenador Pedagógico é fundamentalmente um trabalho de formação continuada em serviço: favorecer a tomada de consciência dos professores sobre suas ações e o conhecimento sobre o meio em que atuam e assim promover o desenvolvimento profissional dos professores. (Fala de um coordenador pedagógico em entrevista realizada por ALMEIDA, 2003, p. 55).

Com base no que foi dito pelo coordenador pedagógico sobre o trabalho da coordenação pedagógica, pode-se ver o quão importe é a formação continuada para o desenvolvimento dos professores e consequentemente do ensino-aprendizagem e que esta deve ser articulada pelos profissionais da coordenação pedagógica.

Tabela 09: RELAÇÕES INTERPESSOAIS NO AMBIENTE ESCOLAR.

\begin{tabular}{|c|c|c|c|c|}
\hline \multirow[b]{2}{*}{ RESPOSTAS } & \multicolumn{2}{|c|}{ campus Iguatu } & \multicolumn{2}{|c|}{ campus Crato } \\
\hline & $\mathrm{N}^{\circ}$ SERV. & $\%$ & $\mathrm{~N}^{\circ}$ SERV. & $\%$ \\
\hline $\begin{array}{l}\text { - Através do contato com os pais, professores, } \\
\text { alunos, coordenadores e nas reuniões pedagógicas; } \\
\text { - Baseadas no princípio de aceitação ao outro da } \\
\text { forma como ele é; } \\
\text { - Maior aproximação entre os setores da instituição; } \\
\text { - São realizadas através de atividades extraclasse e } \\
\text { ações coletivas; } \\
\text { - São harmoniosas; } \\
\text { - Não respondeu }\end{array}$ & $\begin{array}{l}01 \\
01 \\
01 \\
- \\
- \\
- \\
\end{array}$ & $\begin{array}{c}33,33 \\
33,33 \\
33,34 \\
- \\
- \\
- \\
\end{array}$ & $\begin{array}{l}- \\
- \\
02 \\
02 \\
01 \\
\end{array}$ & $\begin{array}{c}- \\
- \\
- \\
40,00 \\
40,00 \\
20,00\end{array}$ \\
\hline TOTAL & 03 & 100 & 05 & 100 \\
\hline
\end{tabular}

Fonte: Questionário aplicado às Coordenações Pedagógicas dos campi Iguatu e Crato - CE 
No quesito nove, indagou-se a forma como são desenvolvidas as relações interpessoais dentro do ambiente escolar, para o qual se obteve os resultados acima, de acordo com a Tabela 09.

Verificou-se na Tabela acima que as relações interpessoais são feitas de forma pacífica e amigável, pois 33,33\% dos entrevistados do campus Iguatu mantêm uma boa relação com os atores do processo (pais, professores, alunos, coordenadores), 33,33\% disseram necessitar de uma aproximação maior entre os diversos setores da instituição e 33,33\% disseram ser baseadas no princípio de aceitação ao outro da forma como ele é. Já com relação ao campus Crato, $40 \%$ dos entrevistados disseram que as relações interpessoais acontecem por meio de atividades extraclasse, $40 \%$ responderam que são harmoniosas e $20 \%$ não responderam.

Pertencer a um grupo não significa ter as mesmas ideias, mas participar da mesma vida... é preciso diferenciar o sentido duplo no qual sempre se realiza a comunicação: no plano das ideias e no plano das vivências. Isto supõe um espírito aberto às ideias dos outros e sobretudo uma grande aceitação das pessoas. (FRITZEN, 1998, p. 37)

Relacionar-se bem com o outro não significa aceitar todos os seus pontos de vista, mas discordar quando necessário, sem perder o respeito e a boa relação com o outro.

Tabela 10 DIFICULDADES DO COTIDIANO ESCOLAR.

\begin{tabular}{l|c|c|c|c}
\multicolumn{1}{c|}{ RESPOSTAS } & \multicolumn{2}{c|}{ campus Iguatu } & \multicolumn{2}{c}{ campus Crato } \\
\cline { 2 - 5 } & $\mathrm{N}^{\circ}$ SERV. & $\%$ & $\mathrm{~N}^{\circ}$ SERV. & $\%$ \\
\hline $\begin{array}{l}\text { - Falta de definição das atribuições da coordenação } \\
\text { pedagógica; falta de compromisso de alguns } \\
\text { profissionais envolvidos no processo; falta de um } \\
\text { planejamento participativo com os atores do processo } \\
\text { ensino-aprendizagem e carência de pessoal; }\end{array}$ & & & & \\
- Disciplina com o internato; & 03 & 100,00 & 02 & 40,00 \\
- O trabalho depender de outros; & - & - & 01 & 20,00 \\
- Não respondeu; & - & - & 01 & 20,00 \\
\hline TOTAL & - & - & 01 & 20,00 \\
\hline
\end{tabular}

Fonte: Questionário aplicado às Coordenações Pedagógicas dos campi Iguatu e Crato - CE

Por fim, na questão dez, indagou-se sobre as dificuldades encontradas no cotidiano escolar para o desenvolvimento das atividades da coordenação pedagógica e obtiveram-se os resultados acima, conforme Tabela 10. 
O primeiro aspecto que pôde ser detectado foi a falta de definição das reais atribuições da coordenação pedagógica. Os entrevistados disseram que faziam trabalhos não inerentes às suas funções, por necessidade da própria instituição, inclusive, foi a carência de pessoal, no campus Iguatu, uma das limitações do trabalho pedagógico. Como o trabalho da coordenação pedagógica só acontece em grupo, foi relatada a dificuldade de realizar esse trabalho, pois nem todos cumprem com o seu dever, dificultando, assim, o trabalho como um todo.

Trabalhar coletivamente, não significa, necessariamente, todos trabalharem juntos o tempo todo. Dependendo dos objetivos comuns, é possível dividir responsabilidades e executar atividades com subgrupos ou mesmo individualmente, desde que se garanta a troca constante de informações e a continuidade do trabalho na direção dos objetivos estabelecidos de comum acordo. (COUTO, 2008, p. 73)

A base do trabalho da coordenação pedagógica é o trabalho coletivo e é necessário que todos tenham consciência do seu compromisso e responsabilidade no processo, pois os resultados alcançados só serão plenamente satisfatórios se contarmos com a participação de todos.

\section{Conclusões}

Após estudos bibliográficos realizados sobre a coordenação pedagógica, constatamos que a organização do trabalho escolar é, indiscutivelmente, importante e necessária para o processo ensinoaprendizagem e que esta se dá na coordenação pedagógica por seus profissionais, que têm como prioridade a busca desta melhoria.

De acordo com os teóricos estudados, observamos que o coordenador pedagógico é peça fundamental no processo ensino-aprendizagem e que na sua função, deve articular as pessoas envolvidas, em especial os docentes, para a reflexão no seu contexto educacional de suas ações, dando a estes, subsídios, suporte pedagógico e orientações que venham contribuir para o crescimento profissional e, consequentemente uma maior qualidade no processo.

Conforme a pesquisa aplicada, após a análise e discussão dos dados, constatou-se que os servidores das coordenações pedagógicas das instituições pesquisadas têm um nível de escolaridade compatível para o cargo, o que leva a crer que estes têm condições de desenvolver um bom trabalho. Além disso, observou-se que as ações das coordenações pedagógicas das instituições pesquisadas são voltadas para o ensino-aprendizagem.

Outro aspecto constatado foi sobre a formação continuada dos professores, que por meio das respostas dadas pelos entrevistados não ficou clara a maneira como esta acontece. Daí a confirmação de que não há uma ação planejada, organizada e contínua nesse sentido. Sabemos que esta deve ser uma ação permanente e contínua da coordenação pedagógica. 
A pesquisa revelou, também, que os servidores têm uma sintonia entre suas atribuições e o papel que desenvolvem em seu cotidiano, embora, executem atividades que não consideram ser inerentes à sua função, por necessidade da instituição, pela carência de pessoal, no caso do campus Iguatu e que as dificuldades encontradas no cotidiano desses servidores são a falta de definição das reais atribuições da coordenação pedagógica, falta de compromisso de alguns para com as atividades a serem executadas, prejudicando, assim, os resultados dos trabalhos, pois os bons resultados se dão, na sua plenitude, com o empenho e dedicação de todos os envolvidos no processo.

\section{Considerações finais}

As coordenações pedagógicas das instituições pesquisadas estão no caminho certo, porém o campus Iguatu desenvolve um trabalho de forma mais integrada entre seus membros.

Sugerimos que os servidores das coordenações pedagógicas pesquisadas tenham oportunidade de se qualificarem, com treinamentos, cursos voltados para sua atividade prática, ou seja, a sua própria formação continuada, dando, assim amplitude ao seu desenvolvimento profissional, aperfeiçoando o seu desempenho com os demais envolvidos no processo.

\section{Referências}

ALMEIDA, Laurinda Ramalho De, Um Dia Na Vida De Um Coordenador Pedagógico De Escola Pública. In: Placco E Almeida Et Al. O Coordenador Pedagógico E O Cotidiano Da Escola. Edições Loyola, São Paulo, 2003.

ANDRÉ, Marli Eliza Dalmazo Afonso De. O Cotidiano Escolar, Um Campo De Estudo. In: Placco E Almeida Et Al. O Coordenador Pedagógico E O Cotidiano Da Escola. Edições Loyola, São Paulo, 2003.

BRASIL. Lei No 9.394, De 20 De Dezembro De 1996. Estabelece As Diretrizes E Bases Da Educação Nacional. Diário Oficial Da União, Brasília, 1996.

COUTO, Bruno Roberta. A Equipe Pedagógica E A Construção Do Trabalho Coletivo. Disponível Em: Atuacao/01_A_Equipe_Pedagogica_E_A_Construcao_Do_Trabalho_Coletivo.Doc. Acessado Em 15 Set. 2008.

Enciclopédia Larousse Cultural. São Paulo: Editora Nova Cultural, 1998.

FERREIRA, Aurélio B. De Holanda. Novo Dicionário Da Língua Portuguesa. Rio De Janeiro: Nova Fronteira, 1985. 
FRANCO, Maria Amélia Santoro. A Práxis Pedagógica Como Instrumento De Transformação Da Prática Docente. Disponível Em: Www.Anped.Org.Br/Reunioes/28/Textos/Gt04/Gt04-46--Int.Rtf. Acessado Em 13 Out. 2008.

FREIRE, Paulo. Educação: Sonho Possível. In: Brandão, Carlos Rodrigues (Org). O Educador: Vida E Morte. $2^{\text {a }}$ Ed. Rio De Janeiro: Graal, 1982.

FRITZEN, José Silvino. Relações Humanas Interpessoais (Nas Convivências Grupais E

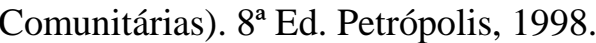

LÜCK, Heloisa. Planejamento Em Orientação Educacional. 10ª Ed. Petrópolis: Vozes, 1991.

ORSOLON, Luzia Angelina Marino. O Coordenador/Formador Como Um Dos Agentes De Transformação Da/Na Escola. Almeida Et Al. O Coordenador Pedagógico E O Espaço Da Mudança. $6^{\text {a }}$ Ed. São Paulo: Loyola, 2007.

PLACCO, Vera Maria Nigro De Souza. O Coordenador Pedagógico No Confronto Com O Cotidiano Da Escola. In: Placco Et Al. O Coordenador Pedagógico E O Cotidiano Da Escola. Edições Loyola, São Paulo, 2003.

PRADA, Luis Eduardo Alvarado. Entrevista Sobre: Formação Continuada. Disponível Em: Http://Www.Uberaba.Mg.Gov.Br/Websemes/Formação/Entrevista.Pdf. Acessado Em 11.11.2008.

SANTOS, Antonio Raimundo Dos. Metodologia Científica: A Construção Do Conhecimento. $4^{\mathrm{a}}$ Ed. Rio De Janeiro: Dp\&A, 2001.

SOUZA, Vera Lúcia Trevisan De. O Coordenador Pedagógico E A Constituição Do Grupo De Professores. In: Almeida Et Al. O Coordenador Pedagógico E O Espaço Da Mudança. $6^{\text {a }}$ Ed. São Paulo: Edições Loyola, 2007.

O Coordenador Pedagógico E O Atendimento À Diversidade. In: Placco Et Al. O Coordenador Pedagógico E O Cotidiano Da Escola. Edições Loyola, São Paulo, 2003.

SOUZA, Vera Lúcia Trevisan, PLACCO, Vera Maria Nigro De Souza. O Coordenador Pedagógico, A Questão Da Autoridade E Da Formação De Valores. Almeida Et Al. O Coordenador Pedagógico E Questões Da Contemporaneidade. $2^{\mathrm{a}}$ Ed. São Paulo: Edições Loyola, 2007.

VASCONCELlos, Celso Dos S. Coordenação Do Trabalho Pedagógico: Do Projeto PolíticoPedagógico Ao Cotidiano Da Sala De Aula. $2^{a}$ Ed. São Paulo: Libertard, 2002.

Como citar este artigo (Formato ABNT):

SOUSA, J.A.G.; ALVES, M.F.M.; FELIPE, M.L.F.M.; ALVES, J.W.F. a Atuação Pedagógica nos Campi de Iguatu e Crato do Instituto Federal de Educação, Ciência e Tecnologia do Ceará. Id on Line Revista de Psicologia, Julho de 2015, vol.9, n.27. p. 07- 25. ISSN 1981-1189.

Recebido: 10/04/2015

Aceito: 22/04/2015 